\title{
BMJ Open Increasing access to care for sick newborns: evidence from the Ghana Newhints cluster-randomised controlled trial
}

\author{
Alexander Manu, ${ }^{1,2}$ Zelee Hill, ${ }^{3}$ Augustinus HA ten Asbroek, ${ }^{4}$ Seyi Soremekun, ${ }^{2}$ \\ Benedict Weobong, ${ }^{1}$ Thomas Gyan, ${ }^{1}$ Charlotte Tawiah-Agyemang, ${ }^{1}$ \\ Samuel Danso, ${ }^{1}$ Seeba Amenga-Etego, ${ }^{1}$ Seth Owusu-Agyei, ${ }^{1,2}$ Betty R Kirkwood ${ }^{2}$
}

To cite: Manu A, Hill Z, ten Asbroek AHA, et al. Increasing access to care for sick newborns: evidence from the Ghana Newhints clusterrandomised controlled trial. BMJ Open 2016;6:e008107. doi:10.1136/bmjopen-2015008107

- Prepublication history for this paper is available online. To view these files please visit the journal online (http://dx.doi.org/10.1136/ bmjopen-2015-008107).

Received 4 March 2015 Revised 9 August 2015 Accepted 19 August 2015

\section{CrossMark}

\footnotetext{
${ }^{1}$ Department of Maternal, Newborn and Adolescent Health cluster, Kintampo Health Research Centre, Ghana Health Service, Kintampo, Ghana ${ }^{2}$ Department of Population Health, London School of Hygiene and Tropical Medicine, London, UK ${ }^{3}$ Faculty of Population Health Sciences, Institute of Global Health, University College London, London, UK ${ }^{4}$ Department of Global Health, Academic Medical Centre, Amsterdam, The Netherlands
}

Correspondence to Dr Alexander Manu; makmanu128@gmail.com

\section{ABSTRACT}

Objectives: To evaluate the impact of Newhints community-based surveillance volunteer (CBSV) assessments and referrals on access to care for sick newborns and on existing inequities in access.

Design: We evaluated a prospective cohort nested within the Newhints cluster-randomised controlled trial. Setting: Community-based intervention involving more than 750000 , predominantly rural, population in seven contiguous districts in the Brong-Ahafo Region, Ghana.

Participants: Participants were recently delivered women (from more than 120000 women under surveillance) and their 16168 liveborn babies. Qualitative in-depth interviews with referral narratives (IDIs) were conducted with 92 mothers, CBSVs and health facility front-desk and maternity/paediatrics ward staff.

Interventions: Newhints trained and effectively supervised 475 CBSVs (existing within the Ghana Health Service) in 49 of 98 supervisory zones (clusters) to assess and refer newborns with any of the 10-keydanger signs to health facilities within the first week after birth; promote independent care seeking for sick newborns and problem-solve around barriers between November 2008 and December 2009.

Primary outcomes: The main evaluation outcomes were rates of compliance with referrals and independent care seeking for newborn illnesses.

Results: Of 4006 sampled, 2795 (69.8\%) recently delivered women received CBSV assessment visits and $279(10.0 \%)$ newborns were referred with danger signs. Compliance with referrals was unprecedentedly high $(86.0 \%)$ with women in the poorest quintile (Q1) complying better than the least poor (Q5):87.5\%(Q1) vs $69.7 \%(Q 5) ; p=0.038$. Three-quarters went to hospitals; $18 \%$ were admitted and $58 \%$ received outpatient treatment. Some $(24 \%)$ mothers were turned away at facilities and follow-on IDIs showed that some of these untreated babies subsequently died. Independent care seeking for severe newborn illness increased from $55.4 \%$ in control to $77.3 \%$ in Newhints zones, especially among $Q 1$ where care seeking almost doubled (95.0\% vs 48.6\%; RR=1.94 (1.32, 2.84);

\section{Strengths and limitations of this study}

- The evaluation used a population-based nested cohort in a trial with an optimum design-cluster randomised controlled trial. The findings are therefore representative of the population and may have external validity in similar settings especially in low and middle-income countries of sub-Saharan Africa and south Asia.

- The use of qualitative methods to evaluate the process and the observed consistency and complementarity with quantitative findings gives strength to these evaluation findings.

- A key limitation was the inability to reconcile referral records with facility records because of poor facility record keeping, where babies who were not treated and sent home had no records of contact with the facility. However, in-depth interviews with professionals in the facilities supported women's account of experiences within the facilities and the general poor quality of care.

$p=0.001$ ). Rates were the highest among rural residents but urban residents complied quicker.

Conclusions: Home visits are feasible and a potentially pro-poor approach to link sick newborns to facilities. Its effectiveness in improving survival hinges on matched improvement in facility quality of care.

Trial registration number: NCT00623337.

\section{INTRODUCTION}

Globally, an estimated $41 \%$ (3.3 million $)^{1}$ of child deaths occur in the first 28 days of life (neonatal period) and $99 \%$ of these are in low and middle-income country (LMIC) settings. ${ }^{2}$ Although causes of neonatal deaths are difficult to ascertain in LMIC settings because contacts are not made with health systems, ${ }^{3}$ three direct causes: infections, 
asphyxia and prematurity or low birthweight and its complications account for $\sim 80 \%$ of these deaths, the majority of which are preventable. ${ }^{1}{ }^{4}$ Infection is the single most important cause contributing to about a quarter (and up to half in high-mortality settings) of all neonatal deaths. ${ }^{5-7}$ Evidence exists that prompt detection and treatment of these infections and effective preventive measures can significantly reduce newborn deaths, but complex interventions are not necessary to save newborn lives. ${ }^{8} 9$

Care seeking for sick newborns is often poor; ${ }^{10-14}$ identified barriers include poor recognition of newborn illnesses, ${ }^{5} 1012 \quad 15$ cultural practices such as seclusion after delivery and a belief in traditional remedies for some newborn illnesses, and geographical and financial inaccessibility to care. ${ }^{12} 1316^{17}$ Most newborn deaths, therefore, occur at home. ${ }^{18-20}$

Family and community practices around care seeking for newborn illnesses can be strengthened by interventions to improve the identification of illness and the likelihood that families access appropriate care. Studies in rural India and Bangladesh have demonstrated that training community health workers/volunteers (CHWs) to promote essential newborn care (ENC) practices and to identify and manage sick newborns (with home treatment and/or referral to hospital) can result in substantial $(30-62 \%)$ reductions in neonatal mortality. ${ }^{20-22}$ In addition, this approach has the potential to be equitable. $^{23}$ No trials have been conducted to date in sub-Saharan Africa where the rates of neonatal mortality are the highest. ${ }^{4}$

The Newhints cluster-randomised controlled trial (CRT) in rural Ghana evaluated the impact of home visits by community-based surveillance volunteers (CBSVs) on ENC practices and neonatal mortality. ${ }^{24}$ It achieved improved coverage of key ENC practices and non-significant reductions of $8 \%$ in neonatal deaths and $15 \%$ in deaths occurring after the first day, the period particularly targeted by the intervention. ${ }^{24}$ The Newhints intervention adopted a three-pronged approach to increase access to care for sick newborns: first, during home visits in the first week of life, the time of the greatest vulnerability for the newborn, ${ }^{4} \mathrm{CBSV}$ weighed and assessed newborns for 10-key danger signs and referred to health facilities when any was present. Doing this sent a strong message to the community about the vulnerability of newborns and reinforced the second approach in which CBSVs promoted care seeking for newborn illnesses by counselling families on danger signs and emphasising the need for urgent action when newborns fell ill. Third, they dialogued and problem-solved with families around barriers to seeking care, both during its promotion and at the time of any referral. In addition, CBSVs counselled families on the importance of saving during pregnancy for emergencies.

In this paper, we present findings on the success of this three-pronged approach, evaluating whether the Newhints intervention has increased access to care for sick newborns (including compliance with referral and independent care-seeking for sick newborns) and in particular assess whether it has reduced inequities in this access.

\section{METHODS}

\section{Study design}

This study is a prospective study nested within the Newhints cluster-randomised controlled trial.

\section{An overview of Newhints trial design and study setting}

Details of the Newhints trial design have already been published. ${ }^{24}{ }^{25}$ In brief, it was a CRT with 49 of 98 supervisory zones randomised for Newhints implementation and 49 acting as controls receiving routine Ghana Health Service (GHS) programmes. In addition, ENC training was conducted in the main health facilities covering both intervention and control zones. The trial covered seven contiguous districts (figure 1) in the Brong-Ahafo Region in central Ghana; an area of $\sim 12000 \mathrm{~km}^{2}$ with a multiethnic and predominantly $(80 \%)$ rural population of more than $700000,{ }^{26}$ engaged primarily in subsistence agriculture. Educational levels were low and communities, mostly served by unpaved roads, lacked modern infrastructure. The four main hospitals located in the relatively urban district capital towns of Techiman, Kintampo, Nkoranza and Wenchi (figure 1) provided comprehensive emergency obstetric and newborn care services and were referral destinations for subdistrict and community-based facilities. Distances between families and hospitals vary from a few metres for urban residents to more than $80 \mathrm{~km}$ from some villages.

Newhints was fully implemented by end of October 2008. Data for impact and process evaluations were obtained through an on-going surveillance system ${ }^{24} 27$ covering 120000 women of child-bearing age. Trial participants were women with babies born between November, 2008 and December, 2009.

\section{The Newhints assessment and referral Training}

Newhints was an integrated intervention package $e^{25}$ which included a three-pronged approach to increasing access to care for sick newborns (figure 2). The core components of Newhints were training more than 450 CBSVs, over 9 days, to identify pregnant women and conduct five focused home visits (two during pregnancy and three on days 1,3 and 7 in the first week after birth) to promote ENC practices, weigh and assess newborns and refer to health facilities if any of the 10 danger signs was present (table 1). To reach babies timely after birth CBSVs left their contact details with families to be contacted whenever women delivered. In addition, they increased the frequency of home visits to women who were in their late pregnancy. CBSVs were provided with portable weighing scales with colourcoded bands: red for weights $<1.5 \mathrm{~kg}$ identifying very 
Figure 1 Map of Ghana

showing Newhints trial districts.

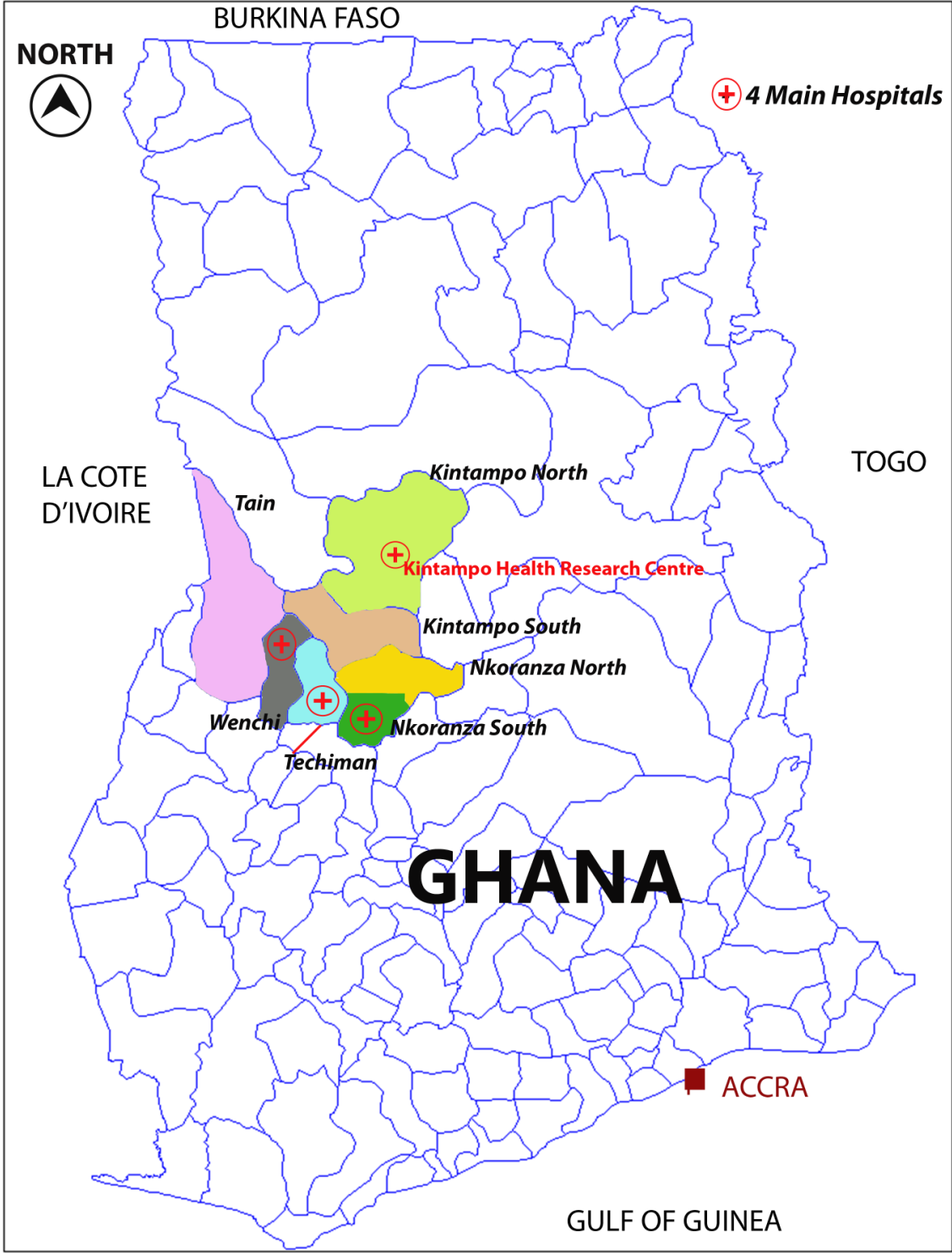

low birthweight (vLBW) babies; yellow for weights of $1.5-2.4 \mathrm{~kg}$ identifying LBW babies; and green for weights of $2.5 \mathrm{~kg}$ and above; a digital thermometer; and a timer.

CBSV training involved interactive discussions, group exercises and practical newborn assessment video exercises using the WHO's Integrated Management of Childhood Illnesses (IMCI) Computerized Adaptation and Training Tool (ICATT). Two training days were dedicated for clinical assessments within hospitals where each CBSV assessed at least two babies.

\section{Referral process}

When CBSVs identified babies with any danger sign, they referred them to health facilities issuing them with a referral card to take along, and counselled on the importance of keeping the baby warm and frequent breastfeeding on the way to the facility. They dialogued and problem-solved around barriers to compliance, followed-up within 24 hours to check compliance and discussed continued
ENC (figure 2). If families had not complied, CBSVs re-assessed and referred again when danger signs persisted.

\section{Promotion of care seeking}

At the second and third postnatal visits, CBSVs additionally promoted the importance of prompt care seeking, and discussed five key illness signs: if the baby has stopped to feed or is not feeding well; if baby is too hot or too cold to touch (fever or hypothermia); if the baby is having difficult or fast breathing (dyspnoea); if the baby has become yellow all over the body (jaundice); and if the baby has become less active (lethargy).

\section{Supervision}

CBSVs were supervised by two trained district-based project supervisors (illness) in each district. DiPS carried out monthly visits to pay CBSV incentives, replenish their stocks and provide supportive supervision by accompanying them into communities and directly observing them carry out home visits; in some of these visits they also carried out repeat assessments of babies. 


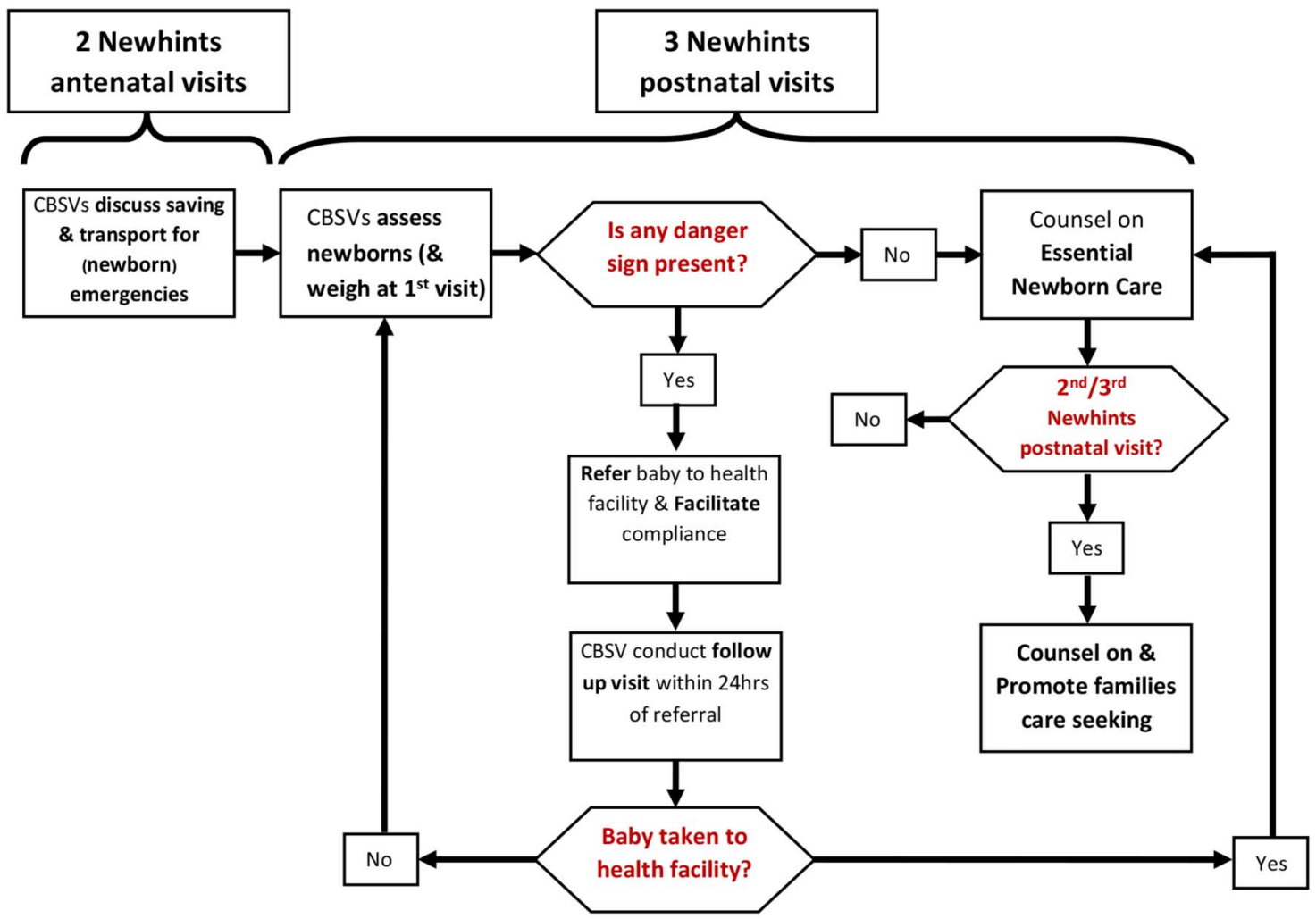

Figure 2 Newhints algorithm for increasing access to care using three-pronged assessment, referral and counselling approach. CBSV, community-based surveillance volunteer.

DiPS completed structured performance records for these directly observed supervision (DOS) visits and gave supportive feedback to reinforce CBSV skills. The DiPS were supervised by Newhints research fellows.

\section{Outcomes}

Two main indicators were used to measure newborn access to care: referral compliance defined as the percentage of families who took their babies to health facilities after CBSV referrals and overall care seeking defined as the percentage of newborns taken to a hospital/clinic among those reported by the mother in the first surveillance visit (usually up to 56 days) after birth as having had severe illness.

\section{Data collection}

The evaluation of compliance achieved in Newhints and assessing whether Newhints has reduced inequities in care seeking for severely ill newborns was based on four types of data (the details are provided in the following sections): surveillance, process evaluation, assessment quality checks (of CBSVs and DiPS) and in-depth interviews with mothers, CBSVs and health professionals.

\section{Informed consent}

Individual informed consent was obtained from all women under surveillance, recently delivered mothers selected for process interviews and the in-depth interviews; CBSVs and their supervisors and health professionals. Interviewers read an information sheet to potential participants in the local language or in English, checked their understanding and answered any questions before consent was requested. Consent forms were read to them and agreement for participation was indicated with a signature or a thumbprint. Participants were assured of confidentiality and their rights to withdraw from the study at any point without prejudice to their position, participation in the main Newhints study or health services received in any facility. They were not required to provide reasons for such decisions.

\section{Surveillance data}

Trained resident-fieldworkers identified pregnancies, births and deaths through 4-weekly home visits to all women of reproductive age. They collected data on sociodemographic characteristics for all pregnancies, including an assets inventory, newborn care practices, morbidity and mortality in the first visit after the birth was identified. From July 2009, this was amended to 8-weekly visits to follow-up pregnant women and their infants.

\section{Process data}

From March 2009, trained field supervisors visited a random subsample of 64 recently delivered women (within 8 weeks of delivery) per week to collect process data on CBSV visits including coverage, assessments, referrals and compliance with referrals including its timing, facilities used and care received. From August 2009 , these data were collected from all women at the 
Table 1 Danger signs for neonatal illness used in Newhints

\begin{tabular}{|c|c|}
\hline Assessment & Danger sign \\
\hline \multicolumn{2}{|l|}{ Ask: } \\
\hline How is the baby feeding? & 1. Baby not breastfeeding well since birth or stopped breastfeeding \\
\hline $\begin{array}{l}\text { History of convulsion or fits } \\
\text { since birth. }\end{array}$ & 2. Baby having convulsed of fitted since birth and not treated in a health facility. \\
\hline \multicolumn{2}{|l|}{ Check for: } \\
\hline Chest movements & 3. Baby having lower chest indrawing on inspiration \\
\hline Palms and soles of the feet & 4. Baby having yellow palms and soles \\
\hline Lethargy/failure to move & 5. Baby very weak and not moving at all or only moving when stimulated \\
\hline Local infections & $\begin{array}{l}\text { 6. Baby having reddening around the umbilicus or pus discharging from the stump, } \\
\text { skin pustules or purulent discharge from the eyes. }\end{array}$ \\
\hline \multicolumn{2}{|r|}{ ' } \\
\hline Breathing rate & 7. Baby breathing too fast: 60 breaths or more per minute validated by a 2 nd count \\
\hline Temperature & 8. Baby having fever: axillary temperature of $37.5^{\circ} \mathrm{C}$ or more \\
\hline Weight & $\begin{array}{l}\text { 9. Baby too cold: axillary temperature of } 35.4^{\circ} \mathrm{C} \text { or less } \\
\text { 10. Birthweight }<1.5 \mathrm{~kg} \text { (in Red zone) }\end{array}$ \\
\hline
\end{tabular}

first surveillance visit after birth. In total, 4006 women in the Newhints zones were interviewed within 8 weeks after the birth.

\section{Assessment quality checks}

With the DOS form, the supervisors (DiPS) recorded the findings of the CBSVs' newborn assessment and their own independent findings during the observation of the CBSV home visits. In July 2009, the DiPS validated the results by comparing outcome of each DiPS' assessment of four babies to an independent assessment conducted by the study clinician (AM) and this took place in the four main hospitals in Kintampo, Nkoranza, Techiman and Wenchi.

\section{In-depth interviews}

In-depth interviews on perceptions and experiences with CBSV assessments, referrals and treatment at the health facility were conducted by the lead author (AM) with 55 recently delivered women whose babies were referred (up to 4 months after birth); purposively selected from the surveillance database to reflect balance with respect to maternal age, rural/urban residence, ethnicity and parity. IDIs on similar topics were also conducted with 21 CBSVs who referred babies, purposively selected to obtain balance on age, gender and place of residence and 15 health facility staff ( 2 front-desk staff, 10 nurses/ midwives, 3 doctors including a paediatrician) from the 4 main hospitals. IDIs were either in the local (Akan) language (women and CBSVs) or English (facility staff). They lasted 60-90 min and were digitally recorded; notes on interview settings were also made.

\section{Data analysis}

Statistical analyses were carried out using Stata V.11.2 (StataCorp. Stata Statistical Software: Release 11.2.
College Station, Texas, USA: StataCorp; 2009). Principal components analysis was conducted on the assets inventory to generate a wealth index, which was used to divide mothers into socioeconomic status quintiles (SEQs). Simple tabulations and cross tabulations were carried out for the outcomes by key maternal (education, place of residence, SEQ), newborn (sex) and other factors (visited by the 2nd day after delivery, issuance of referral card) specific to Newhints. Percentage agreements and $\kappa$ statistics were estimated for agreement between CBSVs and DiPS and between DiPS and clinician assessments. Generalised estimating equations with a $\log$ link function were used to estimate the risk ratios of care seeking by SEQs adjusted for clustering, together with $95 \%$ CIs.

Recordings from the IDIs together with the field notes were transcribed into English and exported into NVIVO V.9.2 (QSR International Pty Ltd. NVivo qualitative data analysis software: Version 9; 2010) for analysis. Analysis involved multiple reading of the transcripts to familiarise with the data, generation of themes (codes), systematic coding and interpretation of text, language, trends and relationships.

\section{Ethical issues}

Newhints and this evaluation received ethical approvals from London School of Hygiene \& Tropical Medicine and Kintampo Health Research Centre. Newhints is registered at clinicaltrials.gov(number=NCT00623337).

\section{RESULTS}

Almost $70 \%$ of 4006 recently delivered women in the process evaluation subsample reported receiving a postnatal visit from their CBSV, and at these visits, almost all CBSVs assessed babies for danger signs (table 2). The quality of assessments was also high; CBSVs achieved near- 
Table 2 CBSV visit and assessment coverage within Newhints zones

\begin{tabular}{lll}
\hline Assessment & Denominator & $\begin{array}{l}\text { Assessments } \\
\text { made (\%) }\end{array}$ \\
\hline $\begin{array}{l}\text { Postnatal visits received } \\
\begin{array}{l}\text { Respiratory rates } \\
\text { measured at postnatal } \\
\text { visits }\end{array}\end{array}$ & $\begin{array}{l}4006 \text { mothers } \\
2795 \text { visits }\end{array}$ & $2795(69.8)$ \\
$\begin{array}{l}\text { Temperature taken at } \\
\text { postnatal visits }\end{array}$ & 2795 visits & $2677(95.8)$ \\
$\begin{array}{l}\text { Weight measured at } \\
\text { postnatal visits }\end{array}$ & 2795 visits & $2651(94.9)$ \\
$\begin{array}{l}\text { Referrals made for } \\
\text { danger signs }\end{array}$ & 2795 visits & $279(10.0)$ \\
$\begin{array}{l}\text { Compliance with referral } \\
\text { CBSV, community-based surveillance volunteer. }\end{array}$ & 279 referrals & $240(86.0)$ \\
\hline
\end{tabular}

perfect agreement with the supervisors $(\kappa=0.85-1.00)$, who in turn agreed almost perfectly with the study clinician $(\kappa>0.9)$.

\section{Referral of sick newborns}

Of 2795 babies assessed at postnatal visits, 279 (10.0\%) had danger signs and were referred for facility care; compliance with these referrals was high with $240(86.0 \%)$ taken to a health facility (table 2). The poorest families complied better than the least poor (figure 3), with an average $88.4 \%$ compliance among the four lower quintiles $(\mathrm{Q} 1-\mathrm{Q} 4)$ compared with $69.7 \%$ compliance among the least poor $(\mathrm{Q} 5)(\mathrm{p}=0.003)$. Although rural families complied marginally more than urban ones, they did so less quickly (figure 4). Their compliance within 1 hour after referral was less than half the level of their urban counterparts $(\mathrm{p}=0.007)$. This slower compliance persisted until after the second day. Maternal education did not affect compliance: more than $85 \%$ of mothers across all educational levels (primary, secondary or higher) and similar among those with/without formal education $(86.4 \%$ vs $85.9 \%$; $\mathrm{p}=0.91)$. 'a baby you have just given birth to who is 'kitikiti' (very small) and is being said to have these problems; it is not an easy thing. We thought if we did not go, something bad might happen to the baby,' [35-year-old mother who complied with referral]

In-depth interviews with non-compliers identified the family's perception that their baby was not severely ill and would improve spontaneously as the commonest reason for non-compliance. Unfortunately, some babies died as a result:

'I thought this was not my first time of having a baby so when he said my baby's breathing was "high", I ignored his advice; If I had listened, probably my child would be alive; the younger girls who listened to his advice have their babies now' [35-year-old mother of three]

CBSVs advised families to go straight to hospitals, and the majority $(74.0 \%)$ did so; this was higher among urban families than rural $(\mathrm{p}=0.01)$. Apart from hospitals, urban residents next patronised clinics (including privately owned facilities) whereas rural residents went to health centres (table 3). Eighteen per cent of babies whose mothers complied with referral were admitted to facilities; this represents $15 \%$ of all referred babies, including the non-compliers ; all admissions except one were to hospitals. Admission rates tended to be higher for babies from lower compared with higher SEQs (figure 3) and from rural compared with urban families ( $17.8 \%$ vs $14.3 \%$; $\mathrm{p}=0.7)$.

About one in four babies were sent home without treatment (table 4). This was most likely to occur at clinics; 8 (44\%) of the 18 babies sent there were not treated. IDIs revealed that some babies had died after contacts with health facilities and being sent home without treatment; for instance 4 of the 32 who went to hospitals and were sent home without treatment subsequently died:

'...I was sad about the way they handled our case because the way the CBSV stressed that I should go to the hospital, I thought he (health professional) was also going
Figure 3 Referral compliance and admission rates by socioeconomic quintile (SEQ) and rural/urban residence.

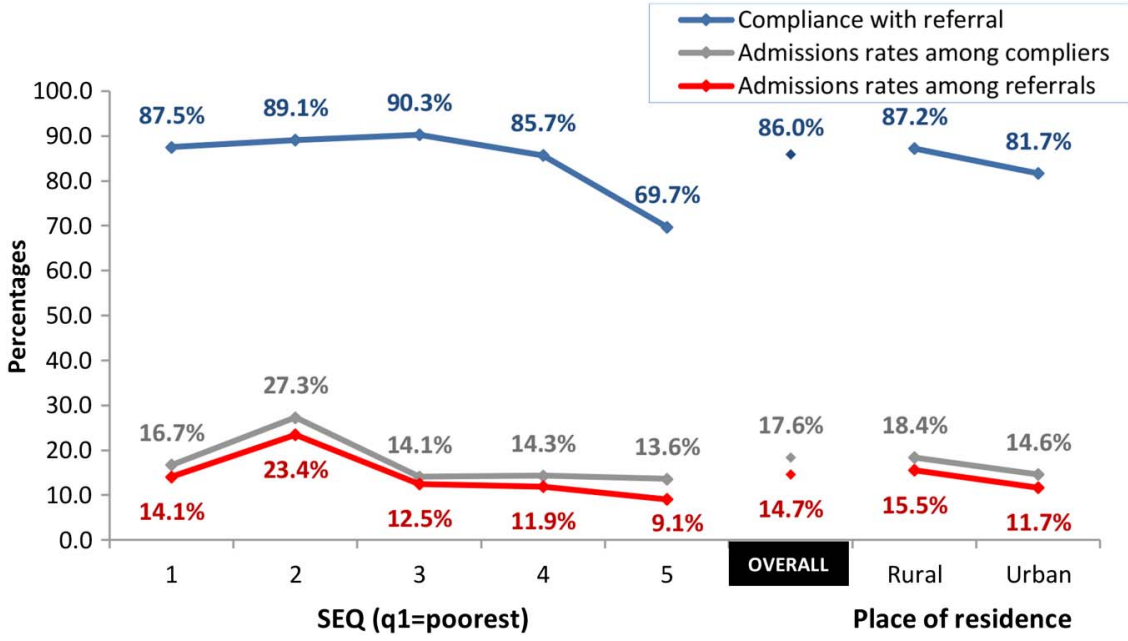


Figure 4 Timing of referral compliance by rural/urban residence.

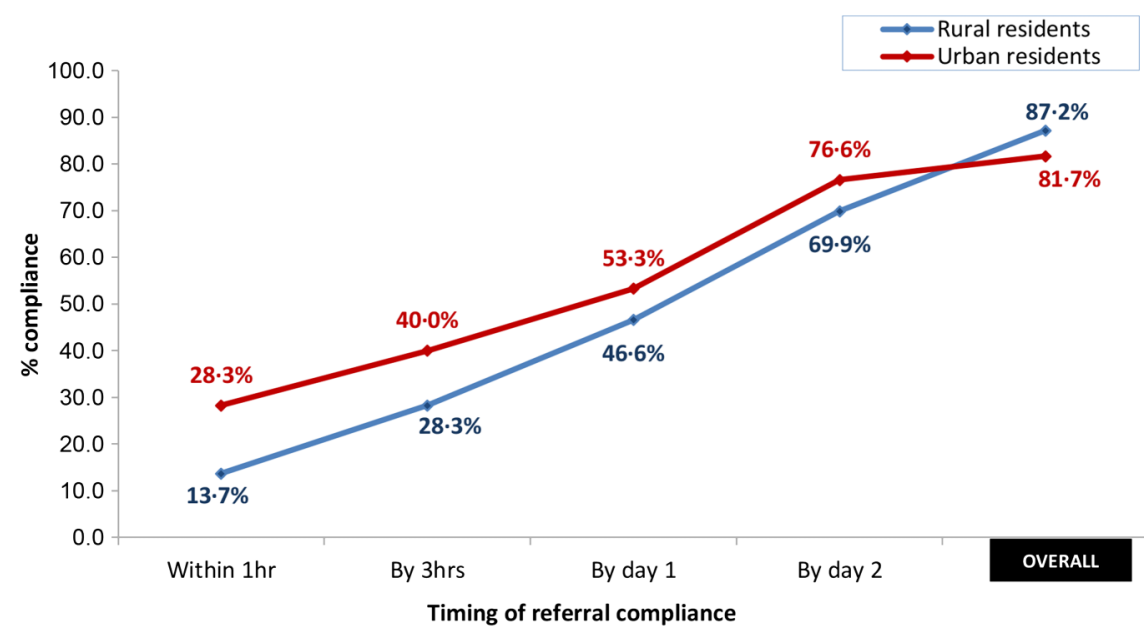

to, at least, count the breaths and check everything again to see if there was any problem; but he did not do anything. They did not treat the baby well.' (20-year-old single mother)

\section{Care seeking for severely ill newborns}

Table 5 and figure 5 show care seeking for babies considered to be severely ill by the mothers. At baseline, there was no difference in care seeking for sick newborns between Newhints and control zones. Care seeking was higher among urban than rural families and increased with increasing SEQ. Post Newhints implementation, care-seeking rates in the control zones were very similar to those at baseline. In contrast, care-seeking rates were $43 \%$ higher $(95 \%$ CI $18 \%$ to $72 \%$; p $<0.0001)$ in Newhints compared with control zones with the largest increases occurring among the poorest (Q1); care seeking was increased by $94 \%(95 \%$ CI of increase $=32 \%$ to $184 \%$; $\mathrm{p}=0.001$ ) by families from the poorest SEQ. As can be seen from figure 5, these increases occurred predominantly among rural and not urban families.

Information on both care-seeking and CBSV assessments was available for a subsample of mothers who provided data for process evaluation. This included 60 of the 132 babies in the Newhints zones perceived as severely ill, of whom 27 had been referred by CBSVs and 33 had been independently recognised as being severely ill. The care-seeking rates for the two groups were similar, $88.9 \%$ and $84.8 \%$, respectively.

Table 3 Facility used by rural/urban place of residence for complying mothers

\begin{tabular}{lccc}
\hline Type of facility & Rural (\%) & Urban (\%) & Total (\%) \\
\hline Four main hospitals & $124(66.3)$ & $37(77.1)$ & $161(68.5)$ \\
Other hospitals & $12(6.4)$ & $1(2.1)$ & $13(5.5)$ \\
Health centre & $40(21.4)$ & $3(6.2)$ & $43(18.3)$ \\
Clinics* & $11(5.9)$ & $7(14.6)$ & $18(7.7)$ \\
Total & $187(100)$ & $48(100)$ & $235 \dagger(100)$ \\
\hline${ }^{*}$ Clinics comprises private clinics, community clinics, Community- \\
Based Health Planning and Services (CHPS) compounds and \\
maternity clinics/home. \\
†Details not available from five mothers who complied.
\end{tabular}

\section{DISCUSSION}

The results of this study show that with adequate training and support, CBSVs were able to identify sick newborns and facilitate compliance to referral even in an area where the majority of families rely on subsistence agriculture and have poor access to care. Newhints substantially increased sick newborn access to facility care; CBSV referrals elicited $86.0 \%$ (95\% CI $81.4 \%$ to $89.9 \%$ ) compliance (unequalled in any previous community newborn intervention) which was prompt and mainly to hospitals. Families' overall care seeking for severe newborn illnesses increased from $55.4 \%$ in control zones (similar to baseline levels) to $77.3 \%$ within Newhints zones. This increased sick newborn access to care was pro-poor with referral compliance and care seeking higher among the poorest (or rural residents) compared with the least poor (or urban residents).

Prerequisites for success of such interventions are assessments being carried out, on time and accurately. Families should also be convinced to take sick newborns for care when asked. With only 14 months of implementation, Newhints achieved $70 \%$ postnatal visit coverage which compares with $73 \%$ attained in the Projahnmo-2 trial (Bangladesh) ${ }^{28}$ - one of the highest attained in a community newborn CRT-although the latter only attained this in the third year of implementation. Assessment coverage in Newhints was almost universal (more than 95\%) and of high quality.

Newhints reduced all-cause neonatal mortality (NMR) by a modest and non-significant $9 \%$; post-day 1 NMR for singleton babies was reduced by $41 \%(2-65 \%, \mathrm{p}=0.04)^{25}$ in the 7 months after improved implementation strategies were introduced. Given the high rates of compliance with referrals and the subsequent dramatic care-seeking differences between intervention and control zones, improved sick newborn access to care could have been a large contributor to any mortality reductions.

Newhints impact on access to care for sick newborns, in the short duration of implementation, was maximal among the poorest and rural families compared with the least poor and urban. This is contrary to predictions 
Table 4 Treatment given by facility type for complying mothers

\begin{tabular}{|c|c|c|c|c|c|}
\hline \multirow[b]{2}{*}{ Management } & \multicolumn{5}{|l|}{ Type of facility used } \\
\hline & Four main hospitals (\%) & Other hospitals (\%) & Health centre (\%) & Clinics (\%) & Total (\%) \\
\hline Admitted & 38 (23.9) & $2(15.4)$ & $1(2.3)$ & $0(0.0)$ & $41(17.6)$ \\
\hline Treated at OPD & 89 (56.0) & $6(46.1)$ & $29(67.4)$ & $10(55.6)$ & $134(57.5)$ \\
\hline Sent home without treatment & $32(20.1)$ & $4(30.8)$ & $12(27.9)$ & $8(44.4)$ & $56(24.0)$ \\
\hline Referred & $0(0.0)$ & $1(7.7)$ & $1(2.3)$ & $0(0.0)$ & $2(0.9)$ \\
\hline Total & $159(100)$ & $13(100)$ & $43(100)$ & $18(100)$ & $233^{*}(100)$ \\
\hline
\end{tabular}

${ }^{*}$ Details not available from seven mothers who complied.

OPD, outpatient department.

of the inverse equity hypothesis ${ }^{29}$ that, in the short term, the impact of such interventions will be maximal among the least poor compared with the poorest. Several reasons could explain the pro-poor results: Newhints was specifically designed to be pro-poor by using existing CBSVs selected and living with community members. In rural settings more than urban, community cohesion is likely to be high and hence CBSV awareness and acceptability of CBSV assessments and referrals may be higher. Geographical distance contributed to delays in care seeking but did not prevent compliance of rural families despite the main hospitals (the preferred care-seeking destination) being located in urban areas.

Directly observed assessments as implemented in Newhints supervision were liable to the Hawthorne effect where volunteers may want to impress supervisors with their assessment skills. This supervisory approach had the advantage of directly reinforcing volunteer assessment skills and confidence but the quality of CBSV assessment may be an overestimate. In previous validation studies, ${ }^{13} \quad 30 \quad 31$ physician assessments lagged behind CHWs' and since newborn danger signs such as breathing rate or chest indrawing can change rapidly, ${ }^{28}$ the validity of comparisons remain questionable. Independent confirmation of referral compliance and care seeking was not feasible: Newhints was not able to be present at facilities to record care seeking and facility recordkeeping was poor with babies sent home without treatment having no contact records.
The Newhints referral process has potential for low specificity as newborns were referred to hospitals when any danger sign was present including signs of local infections. This may increase hospital workload (admissions and bed occupancy), costs and possibly has an impact on quality of care delivered. However, newborn care experts advise prompt care seeking at facilities on the slightest suspicion of infection. ${ }^{32}$ Again, it may be cost-effective treating early disease (requiring minimal resources) to achieve better outcomes than severe disease. Moreover, it would be difficult for programmes to selectively reduce inappropriate care seeking without affecting appropriate ones. ${ }^{33}$ The feasibility and adequacy of referring local infections to lower level facilities or training volunteers in their management should be explored in African settings.

Duality of expert opinions for community-based management of sick newborn persists; some are in favour of community-based treatment while others warn about the possibility of developing drug resistance. ${ }^{34}$ Studies in Asia successfully implemented home-based antibiotic treatment but subsequent referral of severely ill newborns elicited very low and often delayed compliance, ${ }^{20} 2235-39$ with poor subsequent independent care seeking for newborn illnesses. ${ }^{13} 28$ In settings where access to health facilities is low, community treatment may be crucial to improve newborn survival. However, this may require more complex algorithms than those used in Newhints and so may be more difficult to

Table 5 Risk ratios comparing care seeking in Newhints compared with control zones (a) at baseline and (b) within the evaluation cohort

\begin{tabular}{|c|c|c|c|c|}
\hline \multirow[b]{3}{*}{ SEQ } & \multicolumn{4}{|c|}{ Care seeking in Newhints vs Control zones } \\
\hline & \multicolumn{2}{|l|}{ Baseline: 2005-2007 } & \multicolumn{2}{|c|}{$\begin{array}{l}\text { Evaluation cohort: November } \\
\text { 2008-December } 2009\end{array}$} \\
\hline & Adjusted RR (95\% Cl) & p Value & Adjusted RR (95\% Cl) & p Value \\
\hline OVERALL & $1.00(0.82$ to 1.24$)$ & 0.93 & $1.43(1.18$ to 1.72$)$ & $<0.0001$ \\
\hline SEQ1 (poorest) & $1.00(0.83$ to 1.21$)$ & 0.99 & 1.94 (1.32 to 2.84$)$ & 0.001 \\
\hline SEQ 2 & 0.95 (0.64 to 1.43$)$ & 0.82 & 1.53 (1.04 to 2.25$)$ & 0.029 \\
\hline SEQ 3 & $1.18(0.87$ to 1.59$)$ & 0.29 & 1.74 (1.20 to 2.51$)$ & 0.003 \\
\hline SEQ 4 & $1.20(0.82$ to 1.76$)$ & 0.35 & $1.10(0.75$ to 1.60$)$ & 0.64 \\
\hline SEQ 5 (least poor) & $0.82(0.63$ to 1.07$)$ & 0.14 & 0.89 (0.59 to 1.35$)$ & 0.60 \\
\hline Interaction of SEQ and intervention group & $\chi_{(4 \mathrm{df})}^{2}=5.60$ & 0.23 & $\chi_{(4 \mathrm{df})}^{2}=9.73$ & 0.045 \\
\hline
\end{tabular}


Figure 5 Care-seeking risk for newborn illness by Newhints versus control across SEQs and by place of residence: $(A)$ baseline \& (B) Newhints cohorts. SEQs, socioeconomic quintile.
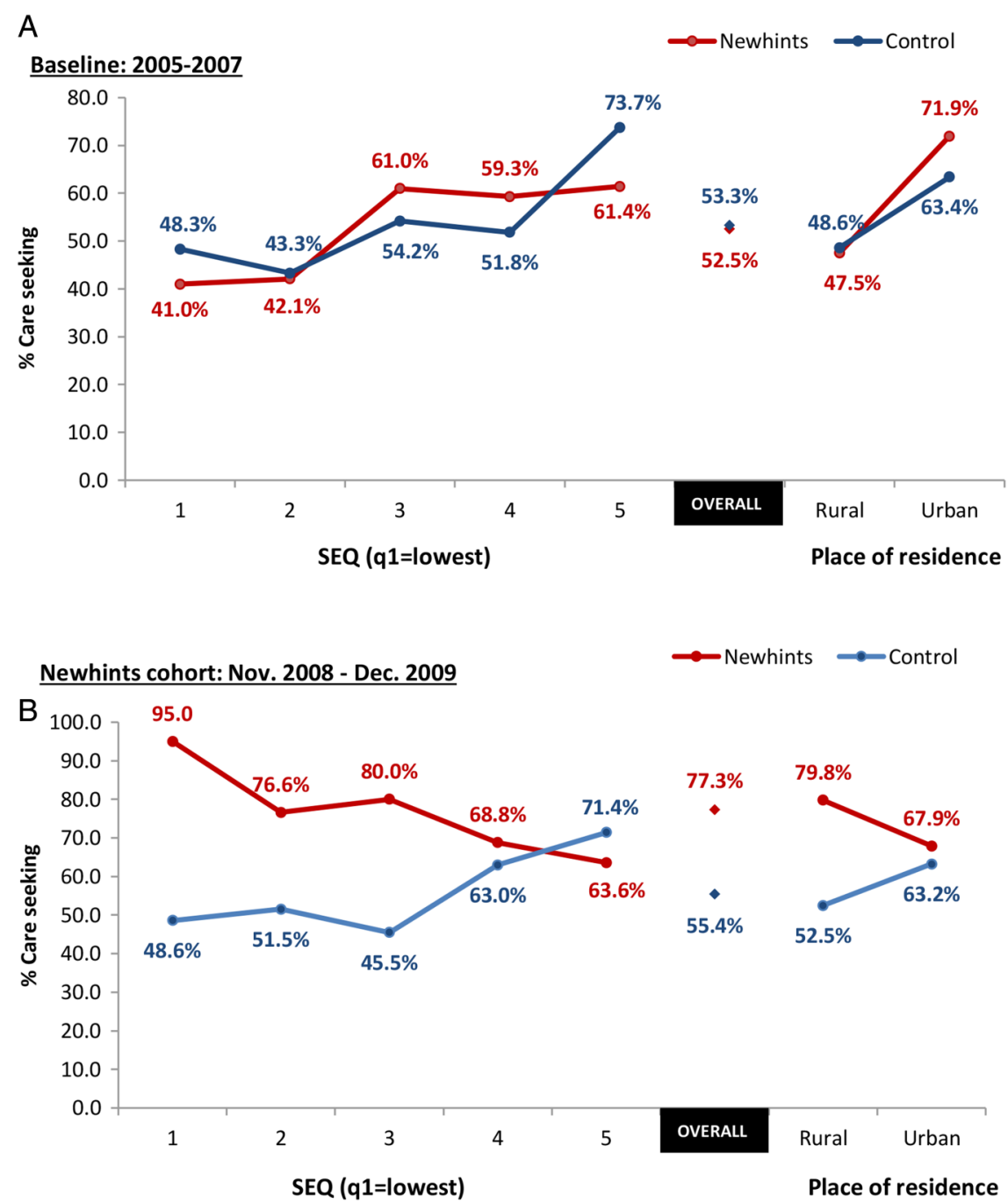

implement at scale. Furthermore, if CHWs treat rather than refer sick babies, this may appear to undermine messages that care seeking at health facilities is important when families perceive their babies to be ill in the absence of the CHW.

In spite of the increased access to care for sick newborns, Newhints achieved only modest reductions in NMR. ${ }^{25}$ Substantial delays at health facilities before first health worker contact, lack of requisite examination before sending babies back home without treatment, some of whom subsequently died, raised questions about the quality of health facility newborn care in the Newhints trial area. A subsequent assessment of newborn care in facilities within the trial area confirmed that despite the Newhints-facilitated ENC training, quality was poor. ${ }^{40}$ Quality newborn care at facilities is an imperative if community assessment and referral of sick babies is to succeed in saving newborn lives. ${ }^{8}$ Furthermore, if high quality is not guaranteed, it may fuel community mistrust in health services for newborns and impact adversely on care-seeking practices. Sri Lanka reduced neonatal mortality from 75.5 (1945) to 12.9 (1991) only through coupling high-care seeking with good quality and accessible healthcare. ${ }^{33}$
In conclusion, the Newhints trial provides evidence showing that implementing community volunteerfacilitated referral at scale within health system settings in sub-Saharan Africa is feasible and potentially pro-poor. It has demonstrated that home visits by community volunteers are an effective approach, at scale, for improving access to care for sick newborns. Harnessing the potential of CBSVs to link communities to health facilities through facilitated referrals is feasible, acceptable and pro-poor but must be matched with improved quality of newborn care within health facilities.

Acknowledgements The authors express their gratitude to the management and staff of the Kintampo Health Research Centre and the London School for the various ways they contributed to make this study a success particularly Angela Vega, the administrator. They also thank the Commonwealth Scholarship Secretariat for supporting the corresponding author on a scholarship to complete this work. They also extend their thanks to the leaders and people in the seven districts of the Brong-Ahafo Region of Ghana where this work was conducted.

Contributors The paper was drafted by AM, and reviewed and approved by all authors. BRK, AM, CT-A, SO-A and ZH were responsible for the design of the Newhints trial. AM, ZH, AHtA, CT-A and BRK were responsible for the data collection instruments. AHtA, AM, CT-A, BW, TG, SS and SO-A were responsible for Newhints trial conduct. AM, SD, SAE, SS, BRK and AHtA were responsible for database design and management; and AM for carrying out the analyses. 
Funding The Newhints Home Visits CRT was funded by the WHO; Save the Children's Saving Newborn Lives programme from The Bill \& Melinda Gates Foundation and UK Department for International Development. Funders had no role in data collection, data analysis or in the writing of the manuscript. The corresponding author had full access to all data and, together with the last author, the final responsibility to submit for publication.

Competing interests None declared.

Patient consent Obtained.

Ethics approval Ethics Review Committees of the World Health Organisation, London School of Hygiene and Tropical Medicine \& Kintampo Health Research Centre.

Provenance and peer review Not commissioned; externally peer reviewed.

Data sharing statement No additional data are available.

Open Access This is an Open Access article distributed in accordance with the Creative Commons Attribution Non Commercial (CC BY-NC 4.0) license, which permits others to distribute, remix, adapt, build upon this work noncommercially, and license their derivative works on different terms, provided the original work is properly cited and the use is non-commercial. See: http:// creativecommons.org/licenses/by-nc/4.0/

\section{REFERENCES}

1. Oestergaard MZ, Inoue M, Yoshida S, et al. Neonatal mortality levels for 193 countries in 2009 with trends since 1990: a systematic analysis of progress, projections, and priorities. PLoS Med 2011;8 e1001080.

2. Zupan J. Perinatal mortality in developing countries. N Engl J Med 2005;352:2047-8.

3. Darmstadt GL, Zaidi Anita KM, Stoll B. Neonatal infections: a global perspective. In: Remington JS, Klein JO, Wilson CB, Nizet V, Maldonado Y, eds. Infectious diseases of the fetus and Newborn infant. 7th edn. Philadelphia: Saunders, 2011:24.

4. Lawn JE, Cousens S, Zupan J, Lancet Neonatal Survival Steering T. 4 million neonatal deaths: when? Where? Why? Lancet 2005;365:891-900.

5. Qazi SA, Stoll BJ. Neonatal sepsis: a major global public health challenge. Pediatr Infect Dis J 2009;28(Suppl):S1-2

6. Thaver D, Zaidi AK. Burden of neonatal infections in developing countries: a review of evidence from community-based studies. Pediatr Infect Dis J 2009;28(Suppl):S3-9.

7. UNICEF. Levels \& trends in child mortality: estimates developed by the UN Inter-agency group for child mortality estimation-2014 Report. United Nations Children's Fund, 2014.

8. Darmstadt GL, Bhutta ZA, Cousens S, et al. Evidence-based, cost-effective interventions: how many newborn babies can we save? Lancet 2005;365:977-88.

9. Stoll BJ. The global impact of neonatal infection. Clin Perinato 1997;24:1-21.

10. Syed U, Khadka N, Khan A, et al. Care-seeking practices in South Asia: using formative research to design program interventions to save newborn lives. J Perinatol 2008;28(Suppl 2):S9-13.

11. Sutrisna B, Reingold A, Kresno S, et al. Care-seeking for fatal illnesses in young children in Indramayu, west Java, Indonesia. Lancet 1993;342:787-9.

12. Bazzano AN, Kirkwood BR, Tawiah-Agyemang C, et al. Beyond symptom recognition: care-seeking for ill newborns in rural Ghana. Trop Med Int Health 2008;13:123-8.

13. Bang AT, Bang RA, Baitule S, et al. Burden of morbidities and the unmet need for health care in rural neonates-a prospective observational study in Gadchiroli, India. Indian Pediatr 2001;38:952-65.

14. Kumar V, Mohanty S, Kumar A, et al. Effect of community-based behaviour change management on neonatal mortality in Shivgarh, Uttar Pradesh, India: a cluster-randomised controlled trial. Lancet 2008;372:1151-62.

15. Choi Y, El Arifeen S, Mannan I, et al. Can mothers recognize neonatal illness correctly? Comparison of maternal report and assessment by community health workers in rural Bangladesh. Trop Med Int Health 2010;15:743-53.

16. Okyere E, Tawiah-Agyemang C, Manu A, et al. Newborn care: the effect of a traditional illness, asram, in Ghana. Ann Trop Paediatr 2010;30:321-8.
17. Awasthi S, Srivastava NM, Pant S. Symptom-specific care-seeking behavior for sick neonates among urban poor in Lucknow, Northern India. J Perinatol 2008;28(Suppl 2):S69-75.

18. UNICEF. Maternal and newborn health: where we stand: UNICEF; 2009. Report No.: 978-92-806-4318-3.

19. Martines J, Paul VK, Bhutta ZA, et al. Neonatal survival: a call for action. Lancet 2005;365:1189-97.

20. Bang AT, Bang RA, Baitule SB, et al. Effect of home-based neonata care and management of sepsis on neonatal mortality: field trial in rural India. Lancet 1999;354:1955-61.

21. Bang AT, Reddy HM, Deshmukh MD, et al. Neonatal and infant mortality in the ten years (1993 to 2003) of the Gadchiroli field trial: effect of home-based neonatal care. J Perinatol 2005;25(Suppl 1): S92-107.

22. Baqui $\mathrm{AH}$, El-Arifeen $\mathrm{S}$, Darmstadt $\mathrm{GL}$, et al. Effect of community-based newborn-care intervention package implemented through two service-delivery strategies in Sylhet district, Bangladesh a cluster-randomised controlled trial. Lancet 2008;371:1936-44.

23. Haines A, Sanders D, Lehmann U, et al. Achieving child survival goals: potential contribution of community health workers. Lancet 2007;369:2121-31.

24. Kirkwood BR, Manu A, Tawiah-Agyemang C, et al. NEWHINTS cluster randomised trial to evaluate the impact on neonatal mortality in rural Ghana of routine home visits to provide a package of essential newborn care interventions in the third trimester of pregnancy and the first week of life: trial protocol. Trials 2010;11:58.

25. Kirkwood BR, Manu A, ten Asbroek AH, et al. Effect of the Newhints home visits intervention on neonatal mortality and care practices in Ghana: a cluster randomised controlled trial. Lancet 2013;381:2184-92.

26. Ghana Health Service. Ghana Health Service-Brong Ahafo Region 2005 [cited 11th April 2012]. http://www.ghanahealthservice.org/ region.php?dd=6\&region=Brong\&nbsp;Ahafo\&nbsp;Region.

27. Kirkwood BR, Hurt L, Amenga-Etego S, et al. Effect of vitamin A supplementation in women of reproductive age on maternal survival in Ghana (ObaapaVitA): a cluster-randomised, placebo-controlled trial. Lancet 2010;375:1640-9.

28. Darmstadt GL, El Arifeen S, Choi Y, et al. Household surveillance of severe neonatal illness by community health workers in Mirzapur Bangladesh: coverage and compliance with referral. Health Policy Plan 2010;25:112-24

29. Victora CG, Vaughan JP, Barros FC, et al. Explaining trends in inequities: evidence from Brazilian child health studies. Lancet 2000;356:1093-8.

30. Baqui $\mathrm{AH}$, Arifeen SE, Rosen $\mathrm{HE}$, et al. Community-based validation of assessment of newborn illnesses by trained community health workers in Sylhet district of Bangladesh. Trop Med Int Health 2009;14:1448-56.

31. Darmstadt GL, Baqui $\mathrm{AH}$, Choi $\mathrm{Y}$, et al. Validation of community health workers' assessment of neonatal illness in rural Bangladesh. Bull World Health Organ 2009;87:12-19.

32. Stoll B. Infections of the neonatal infant: pathogenesis and epidemiology. In: Behrman RE, Kliegman RM, Jenson HB, eds. Nelson's Textbook of Paediatrics. 17th edn. Philadelphia: Saunders, W. B, 2004:623-40.

33. Amarasiri de Silva MW, Wijekoon A, Hornik R, et al. Care seeking in Sri Lanka: one possible explanation for low childhood mortality. Soc Sci Med 2001;53:1363-72.

34. Winch PJ, Gilroy KE, Wolfheim C, et al. Intervention models for the management of children with signs of pneumonia or malaria by community health workers. Health Policy Plan 2005;20:199-212.

35. Bang AT, Bang RA, Stoll BJ, et al. Is home-based diagnosis and treatment of neonatal sepsis feasible and effective? Seven years of intervention in the Gadchiroli field trial (1996 to 2003). J Perinatol 2005;25(Suppl 1):S62-71.

36. Bang AT, Bang RA, Tale $\mathrm{O}$, et al. Reduction in pneumonia mortality and total childhood mortality by means of community-based intervention trial in Gadchiroli, India. Lancet 1990;336:201-6.

37. Bhutta ZA, Memon ZA, Soofi S, et al. Implementing community-based perinatal care: results from a pilot study in rural Pakistan. Bull World Health Organ 2008;86:452-9.

38. Bhutta ZA, Soofi S, Cousens S, et al. Improvement of perinatal and newborn care in rural Pakistan through community-based strategies: a cluster-randomised effectiveness trial. Lancet 2011;377:403-12.

39. Bhandari N, Mazumder S, Taneja S, et al. Effect of implementation of Integrated Management of Neonatal and Childhood Illness (IMNCl) programme on neonatal and infant mortality: cluster randomised controlled trial. BMJ 2012;344:e1634.

40. Vesel L, Manu A, Lohela TJ, et al. Quality of newborn care: a health facility assessment in rural Ghana using survey, vignette and surveillance data. BMJ Open 2013;3:e002326. 